\title{
Fetal Ultrasonography of Holoprosencephaly
}

\author{
${ }^{1}$ Anil K Shukla, ${ }^{2}$ Ajit K Reddy
}

\section{ABSTRACT}

Holoprosencephaly (HPE) occurs when the embryonic forebrain (prosencephalon) fails to divide into the cerebral hemispheres. Thus, resulting in a single-lobed brain structure with severe skull and facial defects. In most instances, the malformations are rather severe, and babies die before birth.

An HPE may be categorized into three variants (1) alobar, (2) semilobar, (3) lobar. Cyclopia a severe facial abnormality that is characterized by a single eye at the root of the nose with an associated supraocular proboscis (tubular nose) replacing the missing one.

Keywords: Cyclopia, Holoprosencephaly, Lobar, Proboscis, Single ventricle, Ultrasonography.

How to cite this article: Shukla AK, Reddy AK. Fetal Ultrasonography of Holoprosencephaly. J Med Sci 2018;4(4):109-110.

\section{Source of support: Nil}

\section{Conflict of interest: None}

\section{INTRODUCTION}

Holoprosencephaly is an uncommon condition which presents with severe abnormalities, and hence baby does not survive and usually dies before birth. Antenatal ultrasonography (USG) is the modality of choice.

\section{CASE REPORT}

In our case of a multigravida who presented for routine antenatal scanning revealed very classical findings of single ventricle, fused eyes, and proboscis (Figs 1 to 3 ). No sibling in the family has any similar abnormality.

Prenatal evaluation by means of three- (3D) and fourdimensional (4D) transabdominal USG was performed to identify alobar HPE (Fig. 4). Since no antenatal treatment could be instituted, after parental counseling it was decided to terminate the pregnancy.

\footnotetext{
${ }^{1}$ Professor, ${ }^{2}$ Assistant Professor

${ }^{1}$ Department of Radiodiagnosis, RajaRajeswari Medical College and Hospital, Bengaluru, Karnataka, India

${ }^{2}$ Department of Radiodiagnosis, Kempegowda Institute of Medical Sciences, Bengaluru, Karnataka, India

Corresponding Author: Anil K Shukla, Professor, Department of Radiodiagnosis, RajaRajeswari Medical College and Hospital, Bengaluru, Karnataka, India, Phone: +9193425 08923, e-mail: shookla2007@yahoo.co.in
}

\section{DISCUSSION}

The HPE may be categorized into three variants (1) alobar, (2) semilobar, (3) lobar. Cyclopia a severe facial abnormality that is characterized by a single eye at the root of the

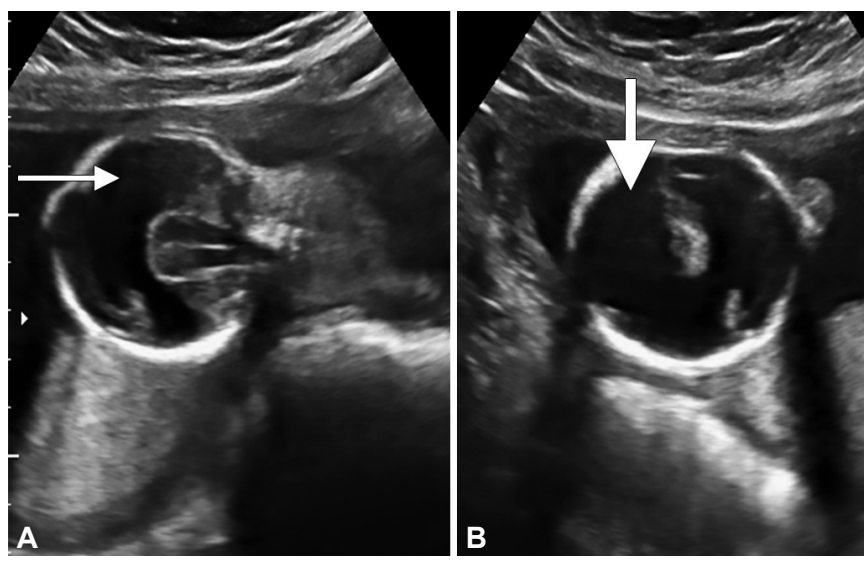

Figs $1 A$ and $B$ : Ultrasonography of fetus showing single ventricle: (A) Transverse (arrow) and (B) Longitudinal axis (arrow)

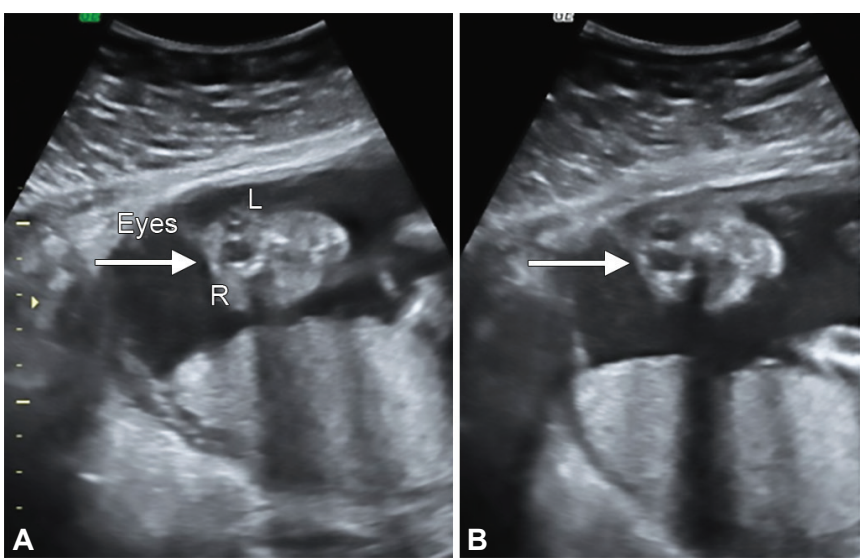

Figs 2A and B: Ultrasonography of fetus showing fused eyes "cyclops" (arrows)

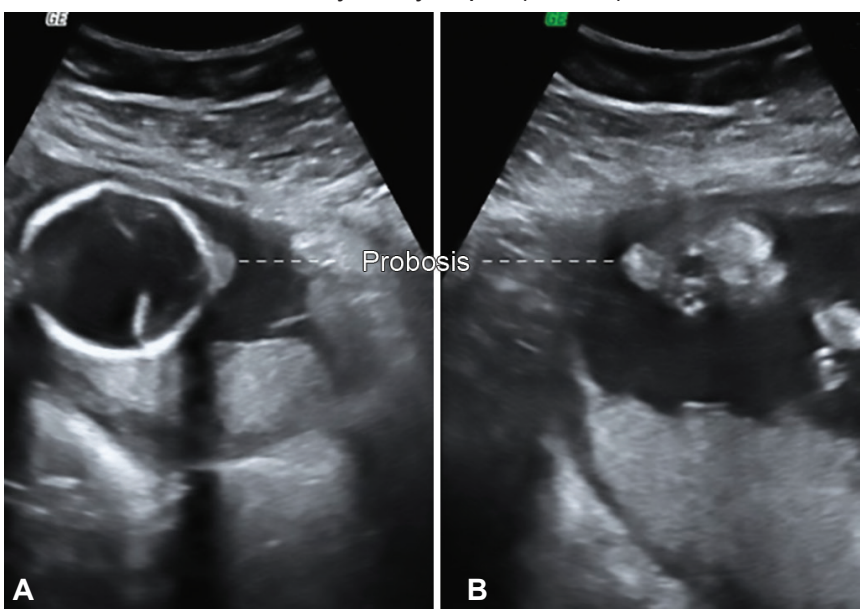

Figs $3 \mathrm{~A}$ and $\mathrm{B}$ : Ultrasonography of fetus showing absent nose and is seen in forehead as "proboscis" (arrows) 

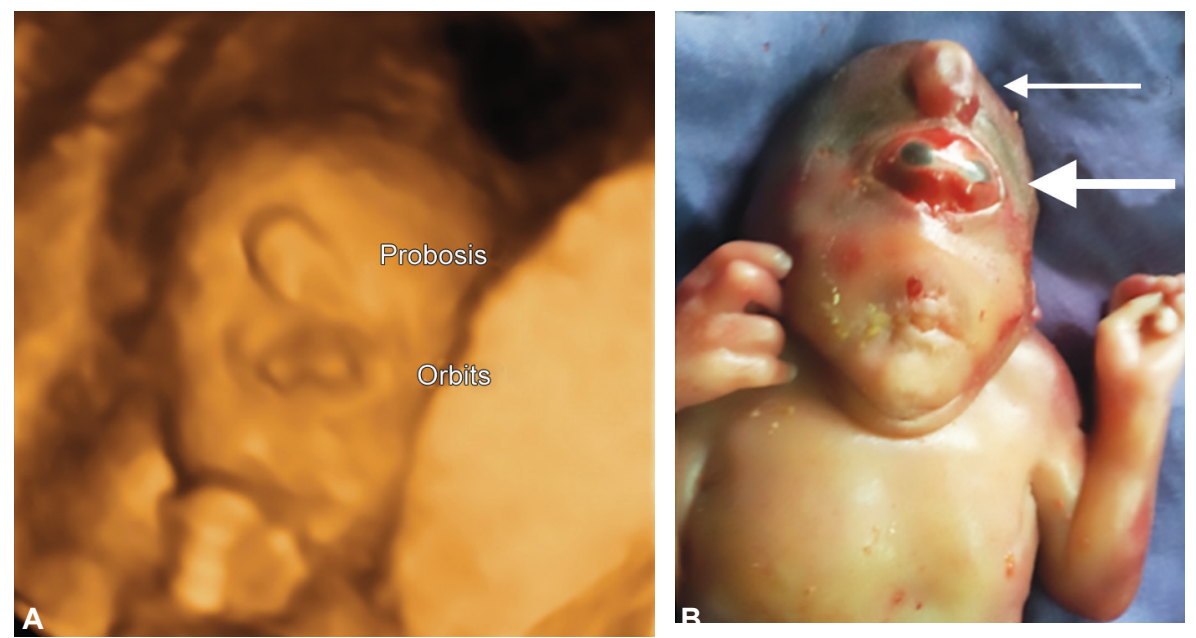

Figs 4A and B: (A) 3D Ultrasonography of fetus; (B) Aborted fetal face showing cyclops and proboscis (arrows)

nose with an associated supraocular proboscis (tubular nose) replacing the missing one. Alobar is often considered as the most serious form where the brain fails to cleave and is associated with facial anomaly and cyclopia. Semilobar is an intermediate form which is less severe where there is partial cleavage of the brain. In the lobar form, there is considerable evidence of a separate cerebral hemisphere noted and is the least severe form. In some instances of lobar holoprosencephaly, the patient's brain may be nearly normal. ${ }^{1,2}$

Syntelencephaly which is sometimes also known as the middle interhemispheric variant results from the improper cleavage of posterior frontal and parietal lobes. If associated with cyclopia it is called cyclocephaly or synophthalmia and is considered a rare entity., ${ }^{2,3}$

About $50 \%$ of the cases have a chromosomal abnormality most common being trisomy 13 (Patau) syndrome and trisomy 18 (Edwards) syndrome. There has been a recent increase in risk in infants born to diabetic mothers. Mutations in the gene encoding the sonic hedgehog protein, which is involved in the development of the central nervous system (CNS) has been attributed for. Some of the risk factors include toxoplasmosis, rubella cytomegalovirus, herpes (TORCH) infections, gestational diabetes, and history of previous miscarriages. ${ }^{1-4}$
Some of the drugs deemed potentially unsafe during pregnancy, such as lithium, thorazine, retinoic acid as well as anticonvulsants are said to have a contributory influence over the occurrence of HPE.,

\section{REFERENCES}

1. Malik R, Pandya VK, Malik S, Awasthi P, Sharma A. Holoprosencephaly: A feature of Patau syndrome. Indian Journal of Radiology and Imaging. 2006 Jan 1;16(1):87-89.

2. KOlluru V, COumary S. Proboscis Lateralis: A Rare Bilateral Case in Association with Holoprosencephaly. Journal of Clinical and Diagnostic Research: JCDR. 2015 Aug;9(8):QD03-4.

3. Salama GS, Kaabneh MA, Al-Raqad MK, Al-Abdallah IM, Shakkoury AG, Halaseh RA. Cyclopia: A rare condition with unusual presentation-a case report. Clinical Medicine Insights: Pediatrics. 2015 Jan;9:CMPed-S21107.

4. Genç M, Genç B, Solak A, Alkılıç L, Uyar M. Alobar holoprosencephaly, proboscis and cyclopia in a chromosomally normal fetus: Prenatal diagnosis and fetal outcome. Italian Journal of Anatomy and Embryology. 2015;120(2): 83-88.

5. Arathi N, Mahadevan A, Santosh V, Yasha TC, Shankar SK. Holoprosencephaly with cyclopia-Report of a pathological study. Neurology India. 2003 Apr 1;51(2):279-282.

6. Wenghoefer M, Anke ME, Sina F, Geipel A, Kuijpers-Jagtman AM, Hansmann H, et al. Prenatal ultrasound diagnosis in 51 cases of holoprosencephaly: craniofacial anatomy, associated malformations, and genetics. The Cleft palate-craniofacial 